\title{
Enhancing Pre-service Teacher's Self-efficacy and Technological Pedagogical Content Knowledge in Designing Digital Media with Self-Regulated Learning Instructional Support in Online Project-Based Learning
}

\author{
Pornsook Tantrarungroj, Praweenya Suwannatthachote \\ Faculty of Education, Chulalongkorn University, Bangkok, Thailand \\ Email: pornsook.t@chula.ac.th
}

Received 2012

\begin{abstract}
This study investigated pre-service teachers' self-efficacy in designing digital media and their technological pedagogical content knowledge (TPCK) for designing digital media using different forms of selfregulated learning instructional support for online project-based learning. The study used a $2 \times 2$ factorial research design. The sample consisted of 232 pre-service teachers from an institution situated in Bangkok, Thailand. The four different forms of self-regulated learning instructional support for online project-based learning were PB + SQ + PA, PB + SQonly, PB + PAonly, and PBonly. Two-way Multivariate Analysis of Variance (MANOVA) was used for data analysis. The results showed significant differences in pre-service teachers' self-efficacy and TPCK posttest scores. No main effect was found between two different self-regulated learning strategies (SQ and PA) upon the means of self-efficacy in designing digital media scores and TPCK scores. The self-regulated learning strategies (SQ and PA) had a statistically significant interaction upon the means of self-efficacy in designing digital media scores while the self-regulated learning strategies (SQ and PA) had no interaction upon the means of the TPCK scores.
\end{abstract}

Keywords: Online Project-Based Learning; Peer Assessment; Pre-Service Teacher; Self-Efficacy; Technological Pedagogical Content Knowledge (TPCK)

\section{Introduction}

Teacher education is designed to equip pre-service teachers with the pedagogical content knowledge, skills, and attitude that are required for classroom teaching. In general, teachers possess teaching expertise that is derived from a combination of pedagogical knowledge, content knowledge, knowledge of students, and knowledge of environmental context (Koehler \& Mishra, 2008; Shulman, 1986). With the growing use of technology in the educational environment, information and communication technology (ICT) has become a powerful tool for extending educational opportunities. The training of teachers in the educational uses of technology appears to be a key component in every improvement plan for education (Angeli \& Valanides, 2009; Magliaro \& Ezeife, 2007). Teachers need to combine technological knowledge, pedagogical knowledge, and content knowledge, when using ICT in classroom. The term "technological pedagogical content knowledge (TPCK)" is used to represent teachers' expertise in technology integration. This is a form of knowledge that is required for the intelligent use of technology in teaching and learning (Angeli \& Valanides, 2009; Chai, Koh, Tsai, \& Tan, 2011; Koehler \& Mishra, 2008). Researchers presuppose that effective technology integration should be formulated by considering the interactions among technology, content, and pedagogy. Thus, pre-service teachers should be grounded not only in the knowledge of content and pedagogy, but also in the knowledge of technology before beginning their teaching field experiences.
Teachers require technological knowledge and technological skills before attempting to utilize technology in class. According to Magliaro and Ezeife (2007), most new teachers have limited knowledge of how to integrate information technology into their professional practice and curriculum even though preservice teachers have formal training in instructional technology. The frequency of teaching with computers is related to teachers' self-efficacy beliefs (Albion, 1999). Self-efficacy means the beliefs a person has about their capability to effectively perform a particular behavior or task (Cassidy \& Eachus, 2002). Bandura's social cognitive theory was used to formulate a theoretical view for studying the computer self-efficacy of pre-service teachers. Four major activities determine the attainment of different levels of self-efficacy: (1) performance accomplishments, (2) vicarious experiences, (3) verbal persuasion, and (4) emotional arousal (Bandura, 1986; Magliaro \& Ezeife, 2007). According to Wall (2004), pre-service teachers with lower computer self-efficacy are more likely to have problems with technology integration and are likely to have problems integrating technology into their own classroom when they finish their teacher education program. Therefore, an increased amount of positive exposure to technology in all areas of academia may generate more favorable attitudes toward computers and educational technology.

Self-regulation is a self-directive processes while self-beliefs are viewed as proactive processes that can be developed and increased during students' self-regulated learning (Fitzpatrick, 1999; Zimmerman, 1989). A person can become a more 
self-regulated learner by acquiring different strategies. According to Zimmerman (1989), self-regulated learning involves the regulation of three general aspects of academic learning, namely, behavior, motivation, and cognition. A combination of these three aspects appears to help people achieve their learning goals. The self-regulated learning strategies include but are not limited to goal setting, time management, help seeking, self-questioning, and peer assessment. Pre-service teachers are expected to be knowledgeable about current technology and to know how it can be used to promote learning. They are also expected to be able to utilize and integrate the technology available into the classroom effectively. Thus, pre-service teachers' strengths and weaknesses as they attempt technology integration should be evaluated in order to determine their potential for the effective use of ICT in the classroom. The current literature on computer self-efficacy lacks a combination of designing digital media and self-regulated learning. This study was intended to investigate pre-service teachers' self-efficacy in designing digital media, and their TPCK in designing digital media using different forms of self-regulated learning instructional support for online project-based learning.

Online project-based learning is a dynamic approach in which pre-service teachers explore real-world situations and challenges. With this type of active and engaged learning, pre-service teachers are stimulated to obtain a deeper knowledge of the content. Active involvement in learning is positively related to learning outcomes (Ge \& Land, 2008; Kramarski \& Michalsky, 2010). Designing digital media requires the designers or teachers to integrate content knowledge, pedagogical knowledge, and technological knowledge that appropriate for the learners' characteristics such as grade level, background knowledge, and level of content.

The self-questioning that was developed based on metacognitive self-questioning (Kramarski \& Michalsky, 2010). It was divided into four categories 1) comprehension questions e.g. "what are learning tasks in digital media?", 2) connection questions e.g. "how do you select a teaching method to deliver content?", 3) strategy questions e.g. "what is your teaching strategy when designing content for this digital media?", and 4) reflective questions e.g. "why and how do you choose instructional strategies for your digital media in order to support learning?".

Tseng and Tsai (2007) found that peer assessment feedback in the form of reinforcement feedback had positive correlation with quality of product improvement. Peer assessment supports team cooperative learning (Fitzpatric, 1999). In the present study, pre-service teachers were required to assess group members' digital media storyboard design using four criteria 1) content, 2) design, 3) attractiveness, and 4) clarification. This research also investigated students' perspective on different formats of self-regulated learning instructional support for online project-based learning. The three instructional support strategies used were: 1) self- questioning and peer assessment (SQ + PA), 2) self-questioning (SQonly), and 3) peer assessment (PAonly).

This study attempted to help pre-service teachers gain higher self-efficacy and TPCK for designing digital media through online project-based learning; and to help them to be confident in their ability to integrate technology in the classroom. It was also designed to help educators understand the benefits of providing different formats for self-regulated learning instructional support for online project-based learning in the teacher education program.

\section{Research Questions}

The purpose of this study was to investigate the effectiveness of self-regulated learning instructional support for online project-based learning on students' self-efficacy in designing digital media. The research questions used were as follows:

Q1: Are there significant differences in the posttest of selfefficacy when designing digital media between pre-service teachers who received different forms of self-regulated learning instructional support?

Q2: Are there significant differences in the posttest of TPCK when designing digital media between pre-service teachers who received different forms of self-regulated learning instructional support?

Q3: What main effect and interaction are found between two different self-regulated learning strategies upon the means of self-efficacy and TPCK when designing digital media scores?

\section{Research Method}

The purposes of this study were 1) to compare the means of self-efficacy and TPCK for designing digital media scores between pre-service teachers who received different forms of selfregulated learning instructional support for online projectbased learning, 2) to study the main effect and interaction between two different self-regulated learning strategies (SQ and PA) upon the means of self-efficacy in designing digital media scores and TPCK scores, and 3) to investigate the behavior of pre-service teachers when collaborating in online-based learning. The study used a $2 \times 2$ factorial research design.

The independent variables, self-questioning and peer assessment strategies, were the two forms of self-regulated learning instructional support for online project-based learning. The dependent variables were pre-service teachers' performance in both self-efficacy for designing digital media and TPCK.

\section{Research Participants}

The participants were pre-service teachers from an institution situated in the center Bangkok, Thailand who enrolled in the pre-service teacher undergraduate course 2726207 ED TECH INFO at Chulalongkorn University during the 2011 academic year. Two hundred and forty-two students agreed to participate in this study; however, 232 were eligible.

The demographics data for the participant shows that $31.5 \%$ were males, and $68.5 \%$ were females. They came from different majors such as science, social science, arts, and music. Participants were randomly assigned to groups on the basis of their majors and TPCK pretest scores in the way that ensured that students with different majors and high, average, and low TPCK ability were included in each group. During the six weeks, pre-service teachers were assigned to work in small groups of 4-5 students.

The four different instructional strategies were:

- Online project-based learning supported by self-questioning and peer assessment (PB + SQ + PA).

- Online project-based learning supported by self-questioning only (PB + SQonly)

- Online project-based learning supported by peer assessment only (PB + PAonly)

- Online project-based learning only (PBonly)

\section{Instrumentation}

The five research instruments used were: 1) a 7-week lesson 
plan, 2) pre/post tests for TPCK in designing digital media, 3) pre/post self-efficacy in designing a digital media survey, 4) self-evaluation questions, and 5) storyboard design rubrics.

1) The 7-week lesson plan was based on the six major steps of the project-based learning approach. Pre-service teachers were randomly assigned to work in small groups of 4-5. Each person was responsible for individual and group work. Online activities took place in the Blackboard Learning Management System. Pre-service teachers completed the self-efficacy in designing digital media survey and the TPCK test during the first week. During the six weeks of the experiment, pre-service teachers were required to use the online communication tools provided for individual work and group work project assignments. Each participant was required to introduce themselves, present and discuss learning resources, design a storyboard for the digital learning object, undertake collaborative work for the group project, and submit their projects. In the last week, preservice teachers worked individually and in groups to evaluate storyboards and to provide feedback to other groups.(Table 1)

2) The pre/post tests for the TPCK in designing digital media were based on ICT-TPCK criteria (Angeli \& Valanides, 2009; Chai, Koh, Tsai, \& Tan, 2011). This test was designed to measure participants' knowledge in four areas: 1) identification of the technique and the teaching methods for the infusion of technology into the design of the digital learning object, 2) identification of technology for transforming the content to be taught into forms that were comprehensible to learners, 3) identification of appropriate pedagogical uses which are difficult or impossible to be implement by traditional means, and 4) selection of appropriate ICT tools and teaching techniques.

3) The pre/post self-efficacy in designing the digital media survey was based on self-efficacy in computer and technological skills (Lee \& Tsai, 2010; Murphy, Coover, \& Owen, 1989; Usher \& Pajares, 2008). The survey was provided through Google Docs, which was used to gather the pre/post self-efficacy for designing digital media data. A five point Likert-type scale, from lowest 1) to highest 5) was used. It was composed of two sections (a) demographic information and (b) self-efficacy for TPCK knowledge integration for designing digital media. The 30 statements in the second section of the survey were designed to evaluate four areas of the respondents' self-efficacy: 1) mastery experience, 2) vicarious experience from peers, 3) social persuasion, and 4) physiological state.

4) The self-evaluation questions were based on metacognitive self-questioning (Kramarski \& Michalsky, 2010). The selfevaluation questions were designed to facilitate respondents' comprehension, to create connections between tasks and comprehension, to stimulate the use of an appropriate strategy for designing digital media, and to reflect on and evaluate their design performance. Pre-service teachers were asked to evaluate themselves during their online group projects.

Table 1.

Group Assignment.

\begin{tabular}{lccc}
\hline \multirow{2}{*}{$\begin{array}{c}\text { Instructional } \\
\text { Strategies }\end{array}$} & \multicolumn{3}{c}{ TPCK pretest scores } \\
\cline { 2 - 4 } & High & Average & Low \\
\hline PB+SQ+PA & 14 & 30 & 15 \\
PB+PAonly & 14 & 29 & 14 \\
PB+SQonly & 13 & 29 & 15 \\
PBonly & 14 & 30 & 15 \\
$\quad$ Total & 118 & 59 & 232 \\
\hline
\end{tabular}

5) The storyboard design rubric was used to evaluate individual and group projects according to four criteria: content, design, attractiveness, and clarification. Each category had three different levels of performance.

\section{Research Procedure (Figure 1)}

Each participant completed the pretest TPCK and self-efficacy in designing digital media survey at the beginning of the study. Pre-service teachers were randomly assigned to groups on the basis of the following research groups: PB + SQ + PA, $\mathrm{PB}+$ PAonly, PB + SQonly, and PBonly. The participants worked collaboratively on online project-based learning under four instructional strategies, with each participant designing a storyboard for the digital learning object.

Online Project-based Learning. Project-based learning is a teaching method that engages students in learning essential knowledge and life-enhancing skills and through an extended, students are involved in an inquiry process around complex questions and carefully designed products and tasks (An \& Kim, 2007). Online Project-based Learning was designed according to the six major steps of the project-based learning approach including 1) discussion of the project topic and needs, 2) inquiry and accumulation for necessary information, 3) definition and selection of guidelines for project development, 4) planning and accumulation of the necessary materials, 5) creation of the storyboard, and 6) reflection on and evaluation of group work.

Upon completing the online project-based learning, the preservice teachers would be able to

1) synthesize, analyze, and derive appropriate topics and content for designing digital media

2) integrate teaching methods and media components for learning object information

3) design the flow and storyboard according to digital media design principles

4) evaluate the appropriateness of different learning object design principles

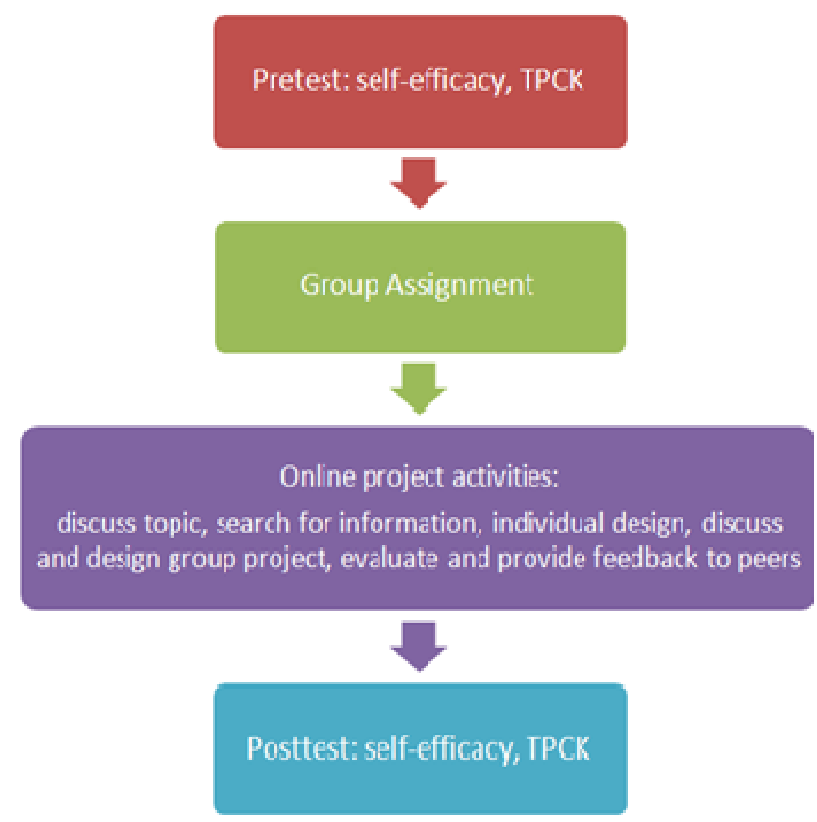

Figure 1.

Research Procedure. 
Tools for Blackboard Group Properties. The Blackboard LMS was used as a learning place for the participants. The following communication tools were provided: Collaboration, File Exchange, Group Discussion Board, and Emails. Figure 2 presents a sample of a screen used during the process. Six steps of the online project-based learning were carried on using the Blackboard Group properties. Pre-service teachers were required to logon and have a discussion with their peers at least 3-4 times per week. The results showed that pre-service teachers used various tools to communicate among group members such as e-mails, Facebook, and personal mobile phones. Most of students $(91.81 \%)$ had a high level of participation behavior for collaborating in an online group project.

\section{Results}

The statistical results showed that pre-service teachers who experienced online project-based learning with different types of self-regulated learning strategies had significantly higher posttest scores for self-efficacy in designing digital media compared to their pretest scores at the .05 level. Table 2 shows the mean scores, standard deviations, and pre and post scores for self-efficacy in designing digital media.

The results demonstrate that pre-service teachers who experienced online project-based learning with different types of self-regulated learning strategies had significantly higher posttest scores statistically for TPCK in designing digital media than pretest scores at the .05 level. Table 3 shows the mean scores, standard deviations, and pre and post scores for TPCK.

There was no main effect between the two different selfregulated learning strategies (SQ and PA) upon the means of self-efficacy in designing digital media scores and TPCK scores;

\begin{tabular}{l} 
Group Tools \\
Collaboration \\
File Exchange \\
Group Discussion Board \\
Send Emai \\
\hline
\end{tabular}

Figure 2.

A screen capture of the online group tools.

Table 2.

Self-efficacy in Designing Digital Media Scores.

\begin{tabular}{lccccc}
\hline $\begin{array}{c}\text { Self-efficacy in designing } \\
\text { digital media scores }\end{array}$ & $\mathbf{N}$ & $\mathbf{M}$ & S.D. & $\mathbf{t .}$ & $\boldsymbol{p}$ \\
\hline PB+SQ+PA & & & & & \\
Pre & 59 & 3.38 & .51 & 7.22 & $.000^{*}$ \\
Post & & 3.85 & 3.85 & & \\
PB+SQonly & 57 & 3.32 & .59 & 5.18 & $.000^{*}$ \\
Pre & & 3.64 & 3.64 & & \\
Post & & & & & \\
PB+PAonly & 57 & 3.39 & .54 & 3.79 & $.000^{*}$ \\
Pre & & 3.66 & 3.66 & & \\
Post & & & & & \\
PB only & 59 & 3.45 & .59 & 3.85 & $.000^{*}$ \\
Pre & & 3.71 & 3.72 & & \\
Post & & & & & \\
Total & 232 & & & &
\end{tabular}

the self-regulated learning strategies (SQ and PA) had no main effect upon the means of self-efficacy in designing digital media scores and TPCK scores; the self-regulated learning strategies (SQ and PA) had statistically interaction upon the means of self-efficacy in designing digital media scores at the .05 level; and the self-regulated learning strategies (SQ and PA) had no interaction upon the means TPCK scores. Table 4 shows the result of two-way Multivariate Analysis of Variance (MANOVA) of SQ and PA affecting self-efficacy and TPCK.

\section{Discussion}

The results show that pre-service teachers who experienced online project-based learning with different types of self-regulated learning strategies had a statistically significantly higher score in the posttest for self-efficacy in designing digital media and TPCK than in their pretest scores at the .05 level. This result indicated that TPCK is a unique body of knowledge (Angeli \& Valanides, 2009) which is the result of the combination and interaction of its contributing knowledge bases. Those three main knowledge will be effective when the teacher training program provides and applies it all as integration knowledge for learners. In this study students became active learners during online project-based learning, they planned, searched, defined,

Table 3.

TPCK in Designing Digital Media Scores.

\begin{tabular}{|c|c|c|c|c|c|}
\hline $\begin{array}{l}\text { TPCK in designing } \\
\text { digital media scores }\end{array}$ & $\mathbf{N}$ & $\mathbf{M}$ & S.D. & t. & $p$ \\
\hline $\begin{array}{c}\mathrm{PB}+\mathrm{SQ}+\mathrm{PA} \\
\text { Pre } \\
\text { Post }\end{array}$ & 59 & $\begin{array}{c}9.27 \\
10.75\end{array}$ & $\begin{array}{l}2.79 \\
2.33\end{array}$ & 4.47 & $.000 *$ \\
\hline $\begin{array}{c}\text { PB+SQonly } \\
\text { Pre } \\
\text { Post }\end{array}$ & 57 & $\begin{array}{c}9.26 \\
10.51\end{array}$ & $\begin{array}{l}2.56 \\
2.12\end{array}$ & 3.15 & $.003^{*}$ \\
\hline $\begin{array}{c}\text { PB+PAonly } \\
\text { Pre } \\
\text { Post }\end{array}$ & 57 & $\begin{array}{c}9.25 \\
10.56\end{array}$ & $\begin{array}{l}2.73 \\
2.49\end{array}$ & 3.28 & $.002 *$ \\
\hline $\begin{array}{c}\text { PB only } \\
\text { Pre } \\
\text { Post }\end{array}$ & 59 & $\begin{array}{c}9.02 \\
10.07\end{array}$ & $\begin{array}{l}2.46 \\
2.48\end{array}$ & 2.72 & $.002 *$ \\
\hline Total & 232 & & & & \\
\hline
\end{tabular}

Table 4.

Two way Multivariate Analysis of Variance SQ \& PA Affecting Selfefficacy and TPCK.

\begin{tabular}{|c|c|c|c|c|c|c|}
\hline Sources & Variables & SS & df & MS & $\mathbf{F}$ & $p$ \\
\hline \multirow{2}{*}{ SQ (A) } & Self-efficacy & 18. & 1 & 18. & 78. & 38. \\
\hline & TPCK & 5.67 & 1 & 5.67 & 1.02 & 31. \\
\hline \multirow{2}{*}{ PA (B) } & Self-efficacy & 34. & 1 & 34. & 1.44 & 23. \\
\hline & TPCK & 7.73 & 1 & 7.74 & 1.39 & 24. \\
\hline \multirow{2}{*}{$(\mathrm{AXB})$} & Self-efficacy & 1.06 & 1 & 1.06 & 4.53 & 03.* \\
\hline & TPCK & 96. & 1 & 95. & 17. & 68. \\
\hline \multirow{2}{*}{ error } & Self-efficacy & 53.28 & 228 & 23. & & \\
\hline & TPCK & 1271.19 & 228 & 5.57 & & \\
\hline \multirow{2}{*}{ Total } & Self-efficacy & 3264.75 & 232 & & & \\
\hline & TPCK & 26717.00 & 232 & & & \\
\hline
\end{tabular}

$* \mathrm{p}<.05$ 
and refined their understanding. During the six-week experiment, pre-service teachers were involved in various activities. The individual assignment required each individual to design a digital media storyboard. This initial assignment promoted pre-service teachers' self-efficacy; later they worked in groups to share ideas and resources. In the students' inquiry process, they needed to search for information, to distinguish related and non-related teaching materials, and to select technological tools for digital media. Through group discussion, they were able to integrate appropriate teaching methods and media components in their storyboard according to digital media designing principles. They also were exposed to examples of good and poor design in digital media through an evaluation activity. These activities along with the self-regulated learning instructional support for the online project-based learning helped the preservice teachers to understand and develop their TPCK competency. It also promoted the pre-service teachers' self-efficacy in designing digital media. By experiencing more information technology-related pedagogy, teachers developed higher levels of ICT self-efficacy (Lee \& Tsai, 2010).

This study found that there was no main effect between two different self-regulated learning strategies (SQ and PA) upon the means for self-efficacy in designing digital media and those for TPCK scores while the self-regulated learning strategies (SQ and PA) had no main effect upon the means for self-efficacy in designing digital media scores and TPCK scores. However, the results showed that (1) the students who received peer assessment strategies (PB + SQ + PA and PB + PAonly) had higher self-efficacy mean scores in designing digital media than those with no-peer-assessment strategies (PB + SQonly and PBonly) and (2) the students who received self-questioning strategies (PB + SQ + PA and PB + SQonly) had higher TPCK mean scores than those with the non-self-question strategies (PB + PAonly and PBonly). The self-regulated learning strategies (SQ and PA) had statistically interaction upon the means of self-efficacy in designing digital media scores at the .05 level. The results were consistent with prior research (Emmer \& Hickman, 1991), indicating that self-efficacy had interaction upon decision, behavior, and performance of teachers. Consequently, teachers should provide two self-regulated learning strategies (SQ and PA) to students who have no previous experience in designing digital media. Once students are able to accomplish a task, they will have stronger self-efficacy beliefs.

Information and communication technology integration in the classroom requires further attention in the teacher training program. For pre-service teachers who have less teaching experience, different formats of self-regulated learning instructional support for online project-based learning is recommended to enhance their self-efficacy and TPCK competency.

\section{REFERENCES}

Albion, P. R. (1999). Self-efficacy Beliefs as an Indicator of Teachers' Preparedness for Teaching with Technology. Retrieved February 29, 2012, from http://www.usq.edu.au/users /albion /papers/site99/1345.html

An, H., \& Kim, S. (2007). The perceived benefits and difficulties of online group work in a teacher education program. International Journal of Instructional Technology and Distance Learning, 4, 3-19. Retrieved December 15, 2011, from http://www.itdl.org/Journal/May_07/article01.htm

Angeli, C., \& Valanides, N. (2009). Epistemological and methodological issues for the conceptualization, development, and assessment of ICT-TPCK: Advances in technological pedagogical content knowledge (TPCK). Computers \& Education, 52, 154-168.

Bandura, A. (1986). Social foundations of thought and action: A social cognitive theory. Englewood Cliffs, NJ: Prentice-Hall.

Cassidy, S., \& Eachus, P. (2002). Developing the computer user self-efficacy (CUSE) scale: Investigating the relationship between computer self-efficacy, gender and experience with computers. Journal of Educational Computing Research, 26, 133-153.

Chai, C. S., Koh, J. H. L., Tsai, C., \& Tan, L. L. W. (2011). Modeling primary school pre-service teachers' technological pedagogical content knowledge (TPACK) for meaningful learning with information communication technology (ICT). Computers \& Education, 57, 1184-1193.

Emmer, E. \& Hickman, J. (1991). Teacher efficacy in classroom management. Educational and Psychological Measurement, 51, 755-765.

Fitzpatrick, C. (1999). Students as evaluators in practicum: Examining peer/self-assessment and self-efficacy. Paper presented at the National Conference of the Association for Counselor Education and Supervision, New Orleans, LA.

Ge, X., \& Land, S. M. (2003). Scaffolding students' problem-solving processes in an ill-structured task using question prompts and peer interactions. Educational Technology Research and Development, 51, 21-38.

Koehler, M. J., \& Mishra, P. (2008). Introducing TPCK. In Silverman, N. (Ed.), Handbook of technological pedagogical content knowledge (TPCK) for educators (pp. 1-20). New York: Routledge.

Kramarski, B., \& Michalsky, T. (2010). Preparing preservice teachers for self-regulated learning in the context of technological pedagogical content knowledge. Learning and Instruction. 20, 434-447.

Lee, M. H., \& Tsai, C. C. (2010). Exploring teachers' perceived self efficacy and technological pedagogical content knowledge with respect to educational use of the World Wide Web. Instructional Science, 38, 1-21.

Magliaro, J., \& Ezeife, A. N. (2007). Preservice teachers' preparedness to integrate computer technology into the curriculum. Canadian Journal of Learning and Technology, 33, 95-111. Retrieved December 15, 2011, from

http://www.cjlt.ca/index.php /cjlt/article/view/163/153

Murphy, C. A., Coover, D., \& Owen, S.V. (1989). Development and validation of the computer self-efficacy scale. Educational and Psychological Measurement, 49,893-899.

Shulman, L. S. (1986). Those who understand: Knowledge growth in teaching. Educational Researcher, 15, 4-14.

Tseng, S. C., \& Tsai, C. C. (2007). On-line peer assessment and the role of the peer feedback: A study of high school computer course. Computers \& Education, 49, 1161-1174.

Usher, E. L., \& Pajares, F. (2008). Sources of self-efficacy in school: critical review of the literature and future directions. Review of Educational Research, 78, 751-796.

Wall, A. (2004). An evaluation of the computer self-efficacy of preservice teachers. Unpublished doctoral dissertation. Tennessee State University, Nashville.

Zimmerman, B. J. (1989). A social cognitive view of self-regulated academic learning. Journal of Educational Psychology, 81, 329-339. 